\title{
Role of $17 \beta$-estradiol and/or progesterone on insulin sensitivity in the rat: implications during pregnancy
}

\author{
C González, A Alonso, N Alvarez, F Díaz, M Martínez, \\ S Fernández and $\mathbf{A} M$ Patterson
}

Departamento de Biología Funcional (Fisiología), Facultad de Medicina, Universidad de Oviedo, Oviedo, Spain

(Requests for offprints should be addressed to C González, Departamento de Biología Funcional (Fisiología), Facultad de Medicina, Universidad de Oviedo, C/Julián Clavería s/n 33006 Oviedo, Spain; Email: tinog@correo.uniovi.es)

\begin{abstract}
The mechanism for the development of insulin resistance in normal pregnancy is complex and is associated with serum levels of both progesterone and $17 \beta$-estradiol. However, it remains unclear whether estrogens alone or progestins alone can cause insulin resistance, or whether it is a combination of both which produces this effect. We attempted to determine the role played by progesterone and/or $17 \beta$-estradiol on the phenomena of sensitivity to insulin action that take place during pregnancy in the rat. Ovariectomized rats were treated with different doses of progesterone and/or $17 \beta$-estradiol in order to simulate the plasma levels in normal pregnant rats. A euglycemic/ hyperinsulinemic clamp was used to measure insulin sensitivity. At days 6 and 11, vehicle (V)- and progesterone $(\mathrm{P})$-treated groups were more insulin resistant than $17 \beta-$ estradiol (E)- and $17 \beta$-estradiol+progesterone (EP)-treated
\end{abstract}

groups. Nevertheless, at day 16, the V, EP and E groups were more resistant to insulin action than the $\mathrm{P}$ group. On the other hand, the V, EP and E groups were more insulin resistant at day 16 than at day 6 , whereas the $\mathrm{P}$ group was more insulin resistant at day 6 than at day 16. Our results seem to suggest that the absence of female steroid hormones gives rise to a decreased insulin sensitivity. The rise in insulin sensitivity during early pregnancy, when the plasma concentrations of $17 \beta$-estradiol and progesterone are low, could be due to $17 \beta$-estradiol. However, during late pregnancy when the plasma concentrations of $17 \beta-$ estradiol and progesterone are high, the role of $17 \beta-$ estradiol could be to antagonize the effect of progesterone, diminishing insulin sensitivity.

Journal of Endocrinology (2000) 166, 283-291

\section{Introduction}

Gestation is a highly important event in the life of mammals, and many metabolic and hormonal changes take place in this period (Herrera et al. 1991, Fernández et al. 1993, Metcalfe et al. 1994), including adaptations of carbohydrate metabolism characterized by a progressive state of insulin resistance that impedes maternal glucose utilization and consequently increases glucose fluxes to the developing fetus (Bliss et al. 1990, Kauffman et al. 1991, Parsons et al. 1992, Baaziz \& Curry 1993). Pregnancy represents a severe stress test of carbohydrate tolerance. An important facet of these changes seems to be the development, in rats, of insulin resistance in the liver and extrahepatic tissues (Leturque et al. 1987). This could give a competitive advantage to the rat uterus during pregnancy, because uterine uptake and placental transport of glucose are relatively unaffected by maternal insulin (Hay et al. 1984, Rankin et al. 1986). The intense flux of maternal glucose to the fetus is partially compensated by maternal hyperphagia (Gutiérrez et al. 1991, Fernández et al. 1993), but the mother is also forced to develop mechanisms that reduce glucose consumption by her own tissues (Leturque et al. 1986). The mechanism(s) by which plasma insulin is elevated in pregnancy is still largely unknown. The process for development of insulin resistance in normal pregnancy is complex and is associated, at least in part, with increasing maternal serum levels of both progesterone and $17 \beta$-estradiol (Howell et al. 1977) or progesterone alone (Sutter-Dub \& Dazey 1979).

Various clinical observations and experimental data from in vitro studies suggest that insulin and sex hormones interact on carbohydrate metabolism (Polderman et al. 1994). However, the effect of the menstrual cycle on this carbohydrate metabolism and insulin sensitivity remains to be determined. Clinical conditions such as pregnancy, where estrogen and progesterone concentrations are markedly raised, have a substantial effect on carbohydrate, lipid, and intermediary metabolism, as well as altering insulin sensitivity (Herrera et al. 1991, Baaziz \& Curry 1993, Metcalfe et al. 1994, Saad et al. 1997). Artificially raised levels of the sex steroid hormones, estrogen and 
progesterone, in women taking the combined oral contraceptive pill were found to affect glucose tolerance and insulin sensitivity (Godsland et al. 1991, Watanabe et al. 1994). The influence of these hormones on the early steps of insulin action have not yet been investigated. However, the hypothesis that has gained most support is that the high insulin levels found in insulin-resistant states can stimulate the ovary, either through binding to classic insulin receptors or by inappropiate binding to the insulin-like growth factor-I receptor through a mechanism known as specificity spillover (Poretsky 1991). It remains unclear whether estrogens alone or progestins alone can cause insulin resistance, or whether it is only a combination of both which produces this effect.

Many findings (Simonson \& Widom 1991, Valdes \& Elkind-Hirsch 1991, Marsden et al. 1996) suggest that estrogen and progesterone can modulate insulin sensitivity in women. These investigations report a poor control of glucose homeostasis in diabetic women during the luteal phase while sensitivity to insulin action in normal women also decreases. It seems clear, therefore, that physiological variations in the concentrations of sex hormones during the menstrual cycle could have an effect on the receptor for insulin binding. All these considerations imply that progesterone is a modulating factor on receptor insulin binding, at least in adipose tissue (Simonson \& Widom 1991, Valdes \& Elkind-Hirsch 1991, Marsden et al. 1996). This interpretation would agree with the reduction in insulin sensitivity attributed to progesterone in women treated with the oral contraceptive pill (Spellacy 1982, Marsden et al. 1996).

The experimental findings of many authors (Leturque et al. 1987, Córdova et al. 1991, Lindheim et al. 1993, 1994) suggest that progesterone administration diminishes sensitivity to the action of insulin, whereas estrogen administration seems to maintain insulin sensitivity in female rats (Holmäng \& Björntorp 1992). Ovariectomy causes a decrease in the glucose disappearance rate, which is restored by estrogen or estrogen+progesterone replacement but not by progesterone alone (Kumagai et al. 1993).

The present study was designed to determine the role played by progesterone and/or $17 \beta$-estradiol on the phenomena of sensitivity to insulin action that take place during pregnancy in the rat.

\section{Materials and Methods}

\section{Animals}

Twelve-week-old virgin female Wistar rats (from the Biotery of Faculty of Medicine, University of Oviedo) weighing 250-280 g, and kept under standard conditions of temperature $\left(23 \pm 3{ }^{\circ} \mathrm{C}\right)$ and humidity $(65 \pm 1 \%)$, and a regular lighting schedule of $12 \mathrm{~h}$ light: $12 \mathrm{~h}$ darkness (0800-2000 h) were used. The animals were fed a standard diet (Panlab A04, PanLab s.I., Barcelona, Spain) and had free access to water. All experimental manipulations were performed between $0930 \mathrm{~h}$ and $1230 \mathrm{~h}$. The experiments were carried out in accordance with the rules of laboratory animal care.

\section{Experimental design}

Three days before initiating the hormonal treatment $($ day -7$)$, the rats were ovariectomized through a midline incision under light ether anesthesia. Ovariectomized rats were separated randomly into four groups: control $(\mathrm{V})$, estradiol (E), progesterone $(\mathrm{P})$ and estradiol+progesterone (EP) and housed individually throughout the experiment.

After surgery, ovariectomized rats were allowed 3 days to recover from surgery stress and for their hormone levels to decrease. From day -4 the rats were injected subcutaneously every $12 \mathrm{~h}(0900 \mathrm{~h}$ and $2100 \mathrm{~h})$ for 20 days with $0.1 \mathrm{ml}$ of a suspension in olive oil/ethanol $(3: 2, \mathrm{v} / \mathrm{v})$ of $17 \beta$-estradiol (Sigma Chemical Co., St Louis, MO, USA), progesterone (Sigma Chemical Co.) or a combination of both hormones. A control group (V) injected with vehicle (olive oil/ethanol 3:2, v/v) was followed in parallel. Different doses of $17 \beta$-estradiol and/or progesterone were injected (Sutter-Dub et al. 1978, Aerts et al. 1980) in order to simulate the plasma levels that we observed in normal pregnant rats (González et al. 1997, 1998). Day 0 represents the start of hypothetic pregnancy.

The hormonal treatment was applied according to the temporal diagram shown in Fig. 1.

Groups (V, E, P and EP) were divided randomly into three subgroups (six animals/subgroup) and one subgroup was killed on days 6,11 and 16. These days were selected as changes were found in sensitivity to the action of insulin during pregnancy in the Wistar rat (González et al. 1997).

\section{Euglycemic insulin clamp}

Clamp procedure was performed in anesthetized rats. After $12 \mathrm{~h}$ of fasting on days 6,11 and 16, the animals were anesthetized with $3.3 \mathrm{ml} / \mathrm{kg}$ body weight i.p. ekytesin $(0.96 \mathrm{~g} / \mathrm{ml}$ sodium pentobarbital, $4.02 \mathrm{~g} / \mathrm{ml}$ chloral hydrate, $2 \cdot 12 \mathrm{~g} / \mathrm{ml}$ magnesium sulfate, $40 \%$ propilenglicol, $10 \%$ ethanol). Body temperature was maintained at $37-$ $38^{\circ} \mathrm{C}$ with heating lamps. The left saphenous vein was catheterized for insulin and glucose infusion.

Approximately $30 \mathrm{~min}$ after the end of surgery and as soon as anesthesia was assured by loss of pedal and corneal reflexes, in order to determine basal insulin concentration, a blood sample $(1 \mathrm{ml})$ was collected from the jugular vein into heparinized tubes, centrifuged at 3000 r.p.m. for 20 min at $4{ }^{\circ} \mathrm{C}$ and plasma was immediately drawn off and stored frozen at $-20^{\circ} \mathrm{C}$ until assayed. A blood sample for the determination of basal blood glucose was collected from the tail. Plasma glucose was measured using an Accutrend System (Accutrend Alpha; Roche Diagnostic S.L., Barcelona, Spain). 


\section{Ovariectomy}

\begin{tabular}{|c|c|c|c|c|c|c|c|c|c|c|c|c|c|c|}
\hline DAYS & -7 & -6 & -5 & -4 & -3 & -2 & -1 & 0 & 1 & 2 & 3 & 4 & 5 & 6 \\
\hline [EST+PROG] & - & - & - & $\mathbf{E} 1+\mathbf{P 1}$ & $\mathbf{E} 1+\mathbf{P 1}$ & $\mathbf{E} 1+\mathbf{P 1}$ & $\mathrm{E} 1+\mathrm{P} 1$ & E1+P1 & $\mathbf{E} 1+\mathbf{P} 2$ & E1+P3 & E1+P4 & E1+P4 & E1+P5 & E2+P5 \\
\hline [EST] & - & - & - & E1 & E1 & E1 & E1 & E1 & E1 & E1 & $\mathbf{E} 1$ & E1 & E1 & E2 \\
\hline \multirow[t]{6}{*}{ [PROG] } & - & - & - & P1 & P1 & P1 & P1 & P1 & $\mathbf{P 2}$ & P3 & P4 & P4 & P5 & P5 \\
\hline & & & & & & & & * & & & & & $\star$ & \\
\hline & DA & & & 7 & 8 & 9 & 10 & 11 & 12 & 13 & 14 & 15 & 16 & \\
\hline & $\mathbf{S T}+\mathbf{P}$ & ROG] & & $\mathrm{E} 2+\mathrm{P5}$ & E2+P5 & E2+P5 & $\mathrm{E} 2+\mathrm{P5}$ & E1+P6 & E1+P6 & E1+P7 & E1+P7 & E1+P7 & & \\
\hline & [ES & & & E2 & E2 & $\mathbf{E} 2$ & E2 & EI & E1 & EI & E1 & E1 & & \\
\hline & [PRC & & & P5 & P5 & P5 & P5 & P6 & P6 & P7 & P7 & P7 & & \\
\hline
\end{tabular}

\section{$\mathrm{P} 1=15.2 \mathrm{mM} ; \quad \mathrm{P} 2=22.9 \mathrm{mM} ; \quad \mathrm{P} 3=30.5 \mathrm{mM} ; \quad \mathrm{P} 4=68.7 \mathrm{mM} ; \quad \mathrm{P} 5=53.5 \mathrm{mM} ; \quad P 6=76.4 \mathrm{mM} ; \quad \mathrm{P} 7=99.3 \mathrm{mM} ;$ $\mathrm{E} 1=0.05 \mathrm{mM} ; \mathrm{E} 2=0.025 \mathrm{mM}$. * $=$ day of killing.}

Figure 1 Temporal diagram of hormonal treatment.

The insulin was infused at a constant rate of $20 \mu \mathrm{l} / \mathrm{min}$ $(0.4 \mathrm{IU} / \mathrm{kg}$ per h) into the left saphenous vein and the blood glucose level clamped at the level measured in the basal state by a variable infusion of glucose through the saphenous vein with a Precidor pump (Precidor Type 5003 Infusion Pump; INFORS AG, Switzerland). Insulin (biosynthetic human insulin Actrapid; Novo Nordisk, Basgsvaerd, Denmark) was dissolved in $0.9 \% \mathrm{NaCl}$ containing $0 \cdot 28 \%$ bovine serum albumin (Sigma Chemical Co.) and $0 \cdot 125 \%$ heparin (sodium heparin 1\%). The infusion of exogenous glucose (12-15\% solution) dissolved in $0.9 \% \mathrm{NaCl}$, was initiated $5 \mathrm{~min}$ after insulin infusion. Blood $(25 \mu \mathrm{l})$ was then sampled from the tail every $5 \mathrm{~min}$ and plasma glucose concentration was determined with an Accutrend System.

Adjustments in the exogenous glucose infusion rate were made to maintain euglycemia by altering the percent dial of the Precidor pump depending on the changes in blood glucose concentrations observed. These alterations were made empirically (Kraegen et al. 1983, Escrivá et al. 1992).

The duration of the experiment was about $1 \mathrm{~h}$ and the euglycemic clamp was easily reached 30-40 min after the beginning of insulin infusion. The total amount of blood necessary for monitoring the blood glucose concentration $(0.5 \mathrm{ml})$ was quite acceptable for an animal of this size.

After the clamp study, blood samples $(4 \mathrm{ml})$ for the determination of final insulin, progesterone and $17 \beta$ estradiol plasma concentrations were collected from the jugular vein into heparinized tubes, centrifuged at 3000 r.p.m. for $20 \mathrm{~min}$ at $4{ }^{\circ} \mathrm{C}$ and plasma was immediately drawn off and stored frozen at $-20^{\circ} \mathrm{C}$ until assayed. The total blood volume taken was $5 \cdot 5-6.5 \mathrm{ml}$ from each animal. Plasma insulin was measured by RIA using a DGR Instruments GmbH (Marburg, Germany) kit for rat insulin. The sensitivity of the assay was $0 \cdot 1 \mathrm{ng} / \mathrm{ml}$, and the intra-assay coefficient of variation was $9 \cdot 32 \%$. The sample was assayed in duplicate. Plasma $17 \beta$-estradiol was measured by RIA using Immuchen kits of cover tubes (ICN Pharmaceuticals Inc., Costa Mesa, USA). The assay sensitivity was $10 \mathrm{pg} / \mathrm{ml}$, and the intra-assay coefficient of variation was $12 \cdot 26 \%$. Plasma progesterone was measured by RIA using Immuchen kits of cover tubes (ICN Pharmaceuticals Inc.). The sensitivity of the assay was $0 \cdot 15 \mathrm{ng} / \mathrm{ml}$, and the intra-assay coefficient of variation was $11 \cdot 48 \%$. The sample was again assayed in duplicate. All samples were measured on the same day.

Finally, samples of different tissues were collected and immediately frozen in liquid nitrogen for future experiments and the animals were killed by bleeding.

\section{Statistics}

Data are expressed as means \pm S.E.M. Intragroup comparisons for the period of hormonal treatment were made using an analysis of variance or Kruskal-Wallis one-way ANOVA test, and the Student-Newman-Keuls test or Mann-Whitney U-Wilcoxon Rank Sum W test. A $P \leqslant 0.05$ was considered as significant. Statistical analysis was performed using SPSS for Windows v.6·01. 


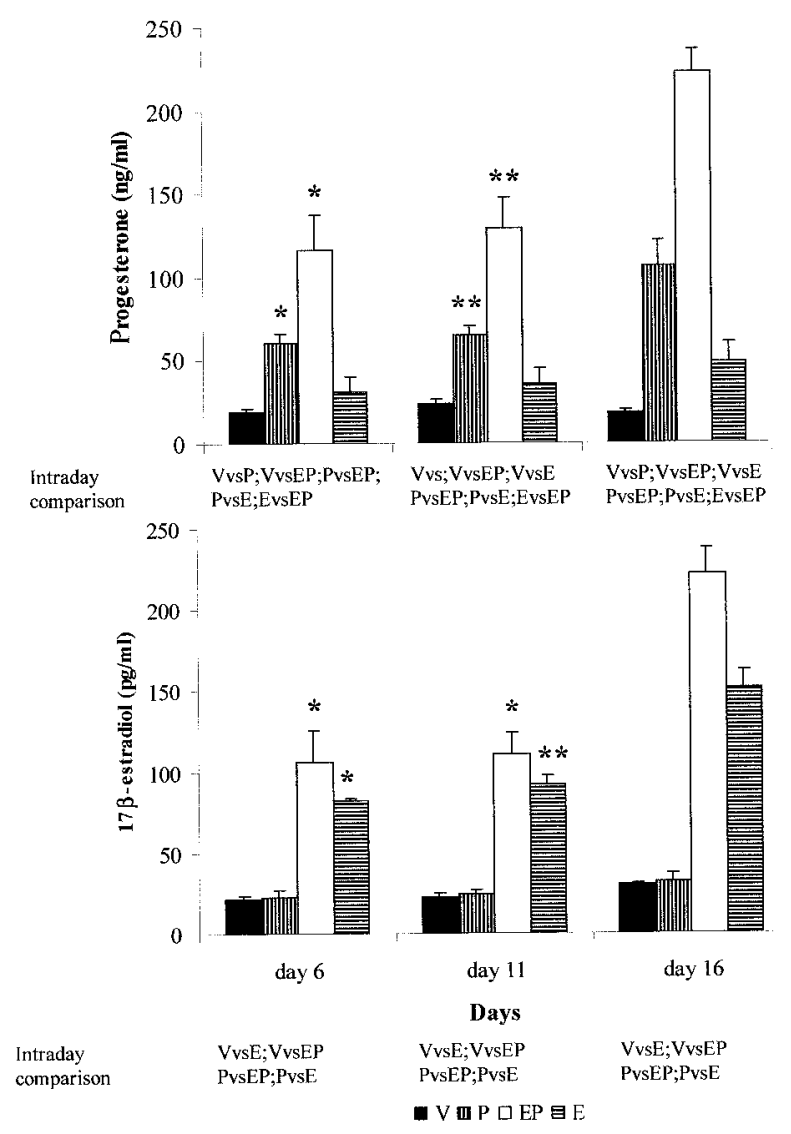

Figure 2 Levels of progesterone and $17 \beta$-estradiol of vehicle (V)-, progesterone $(\mathrm{P})$-, estradiol+progesterone (EP)- and estradiol (E)-treated rats at days 6,11 and 16 of the experiment. Values are means \pm S.E.M. for six animals. Only significant differences are shown. ${ }^{*}=6$ vs $16 ;{ }^{* *}=11$ vs 16 .

\section{Results}

Plasma progesterone and $17 \beta$-estradiol values observed throughout the study are shown in Fig. 2. The plasma levels of progesterone in the $\mathrm{P}$ group were in concordance with normal pregnancy in the rat (González et al. 1997). However, in the EP group these were higher than in normal pregnancy. On the other hand, the plasma levels of $17 \beta$-estradiol were higher in the E and EP groups than in normal pregnancy in the rat (González et al. 1997).

Comparisons of body weight increase can be seen in Fig. 3. The increase in body weight was significantly higher on days 0 to 6 of the experimental period in the V, $\mathrm{P}$ and EP groups compared with days 11 to 16 . No differences were noted in the E group. On days 0 to 6 , the rise in body weight was significantly higher in the $\mathrm{P}$ than in the $\mathrm{EP}$ and $\mathrm{E}$ groups, in the $\mathrm{V}$ compared with the $\mathrm{E}$ group and in the EP compared with the E group. On days 6 to 11 the increase in body weight was significantly lower in the $\mathrm{E}$ than in the $\mathrm{V}, \mathrm{P}$ and $\mathrm{EP}$ groups.

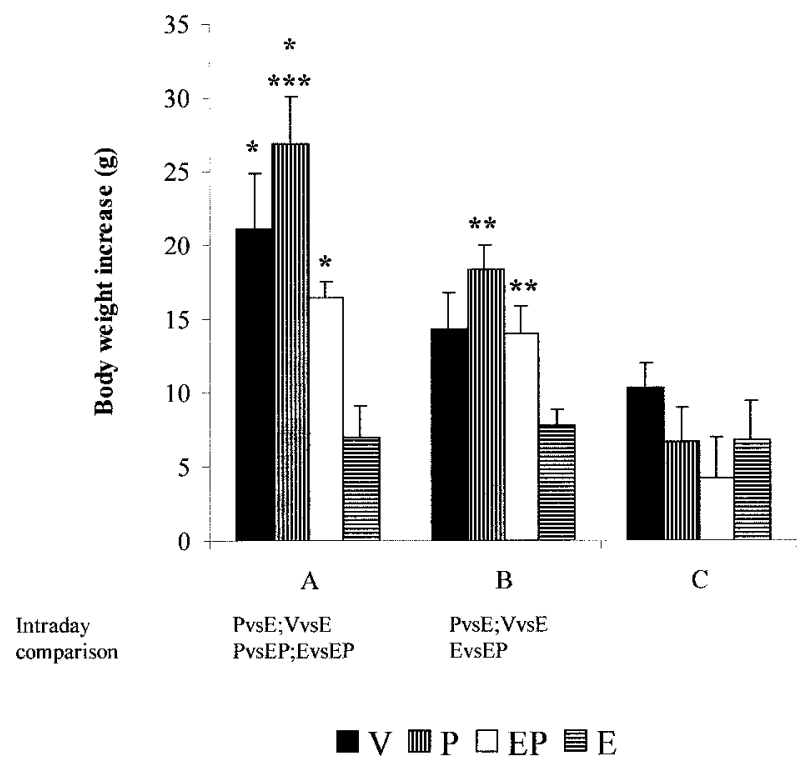

Figure 3 Comparison of increase in body weight of vehicle (V)-, progesterone $(\mathrm{P})$-, estradiol+progesterone (EP)- and estradiol (E)-treated rats. A, B and C=body weight changes from day 0 to 6, day 6 to 11 and day 11 to 16 respectively. Values are means \pm S.E.M. for six animals. Only significant differences are shown. ${ }^{*}=6$ vs $16 ;{ }^{* *}=11$ vs $16 ;{ }^{* *}=6$ vs 11 .

Table 1 shows fasting blood glucose, fasting serum insulin and serum insulin after clamp experiments. Fasting blood glucose levels were observed to be similar between groups and between days of the experimental period.

A significant decrease was found between days 11 and 16 in the fasting serum insulin levels of the EP group. Comparing this parameter for each day, we observed that on days 6 and 11 the levels of fasting serum insulin were significantly higher in the EP and E than in the $\mathrm{V}$ and $\mathrm{P}$ groups. However, on day 16 these differences only showed up between the $\mathrm{P}$ and $\mathrm{EP}$ and the $\mathrm{P}$ and $\mathrm{E}$ groups.

When comparing the groups each day, serum insulin levels after clamp experiments were similar in all groups at day 6. Although at days 11 and 16 this parameter was higher in the $\mathrm{V}$ than in the other groups, no significant differences were noted. A significant increase in the $\mathrm{V}$ and a significant decrease in the EP group were observed between days 6 and 16 .

To investigate insulin resistance in rats at different days of the hormonal treatment, glucose clamp experiments were carried out under euglycemic and hyperinsulinemic conditions. Figure 4 shows the results of the clamp experiments. After insulin infusion, the blood glucose levels increased slightly from 0 to $10 \mathrm{~min}$ in some groups, but from 15-20 min to $60 \mathrm{~min}$ the blood glucose levels clamped around $110 \mathrm{mg} / \mathrm{dl}$ in all cases (Fig. 4A, B and C). On the other hand, on days 6 and 11 the glucose infusion rate of rats treated with vehicle and progesterone alone $(\mathrm{V}$ and $\mathrm{P}$ ) were significantly lower than that of the groups 
Table 1 Fasting blood glucose, fasting serum insulin and serum insulin after clamp experiments of vehicle (V)-, progesterone (P)-, estradiol+progesterone (EP)- and estradiol (E)-treated rats on days 6, 11 and 16 of the experiment. Values are means \pm S.E.M.; there were six animals/group

\begin{tabular}{|c|c|c|c|c|c|}
\hline & Treatment & Day 6 & Day 11 & Day 16 & Comparison \\
\hline \multicolumn{6}{|l|}{ Fasting blood glucose (mg/dl) } \\
\hline & V & $108 \cdot 77 \pm 4 \cdot 00$ & $110 \cdot 00 \pm 3 \cdot 00$ & $103 \cdot 16 \pm 2 \cdot 38$ & \\
\hline & $\mathrm{P}$ & $112 \cdot 71 \pm 6 \cdot 20$ & $113 \cdot 00 \pm 5 \cdot 61$ & $110 \cdot 00 \pm 4 \cdot 23$ & \\
\hline & EP & $110 \cdot 40 \pm 3 \cdot 72$ & $112 \cdot 60 \pm 6 \cdot 83$ & $99 \cdot 60 \pm 1 \cdot 66$ & \\
\hline & $\mathrm{E}$ & $116 \cdot 40 \pm 4 \cdot 82$ & $120 \cdot 80 \pm 5 \cdot 65$ & $107 \cdot 80 \pm 2 \cdot 59$ & \\
\hline \multicolumn{6}{|l|}{ Fasting serum insulin $(\mathrm{ng} / \mathrm{ml})$} \\
\hline & $\mathrm{V}$ & $0.67 \pm 0.19$ & $0 \cdot 72 \pm 0 \cdot 18$ & $0 \cdot 72 \pm 0 \cdot 29$ & \\
\hline & $\mathrm{P}$ & $0.59 \pm 0 \cdot 17$ & $0.57 \pm 0 \cdot 17$ & $0 \cdot 32 \pm 0 \cdot 008$ & \\
\hline & $\mathrm{EP}$ & $2 \cdot 59 \pm 0 \cdot 12$ & $3 \cdot 76 \pm 0 \cdot 81$ & $1 \cdot 72 \pm 0 \cdot 38$ & $11 \mathrm{vs} 16$ \\
\hline & $\mathrm{E}$ & $2 \cdot 17 \pm 0 \cdot 23$ & $2 \cdot 21 \pm 0 \cdot 29$ & $1 \cdot 74 \pm 0 \cdot 23$ & \\
\hline & Comparison & VvsEP; VvsE; & VvsEP; VvsE; & PvsEP; PvsE & \\
\hline & & PvsEP; PvsE & PvsEP; PvsE & & \\
\hline \multicolumn{6}{|l|}{ Serum insulin after clamp experiments ( $\mathrm{ng} / \mathrm{ml})$} \\
\hline & V & $2 \cdot 15 \pm 0 \cdot 55$ & $7 \cdot 45 \pm 1.97$ & $11 \cdot 54 \pm 3 \cdot 78$ & 6vs16 \\
\hline & $\mathrm{P}$ & $3 \cdot 29 \pm 0 \cdot 97$ & $4.53 \pm 0.66$ & $5 \cdot 31 \pm 1 \cdot 63$ & \\
\hline & $\mathrm{EP}$ & $4 \cdot 46 \pm 0 \cdot 81$ & $2 \cdot 35 \pm 0 \cdot 33$ & $2 \cdot 43 \pm 0 \cdot 21$ & 6vs $11 ; 6 v s 16$ \\
\hline & $\mathrm{E}$ & $3 \cdot 31 \pm 0 \cdot 20$ & $5 \cdot 19 \pm 0 \cdot 20$ & $4 \cdot 05 \pm 2 \cdot 40$ & \\
\hline
\end{tabular}

Only significant differences are shown.

treated with estradiol (EP and E), indicating the existence of insulin resistance in the $\mathrm{V}$ and $\mathrm{P}$ groups (Fig. 4D and $\mathrm{E}$ ). However, on day 16, the infusion rate of rats treated with progesterone alone was significantly higher than that of the other groups (V, EP and E), revealing the existence of insulin resistance in the the V, EP and E groups (Fig. 4F).

Figure 5 shows the comparison of glucose infusion rates on days 6,11 and 16 of the experiment. In the $V$ group the glucose infusion rate significantly decreased between days 6 and 16. In the EP and E groups this rate was similar between days 6 and 11, but significantly diminished between days 6-16 and 11-16. However, a significant increase was found in the $\mathrm{P}$ group between days 6-16 and $11-16$.

\section{Discussion}

Progesterone and estradiol have been implicated as etiologic factors in the development of insulin resistance during pregnancy (Baaziz \& Curry 1993, Kumagai et al. 1993, Sorenson et al. 1993, Nelson et al. 1994), but the effect of both hormones on glucose homeostasis remains relatively unclear. In this study, we have tried to clarify the separate roles of $17 \beta$-estradiol and progesterone on glucose homeostasis.

The plasma levels of $17 \beta$-estradiol and progesterone in the EP group were higher than expected with the administered doses (Fig. 2). In spite of these levels, the profiles of both hormones in this group were similar to pregnancy, that is to say, similar plasma concentrations between days 6 and 11 and a significant increase between days 11 and 16, in agreement with previous studies in rats
(Sutter-Dub et al. 1978, Aerts et al. 1980, González et al. 1997, 1998). The level of $17 \beta$-estradiol was also higher in the $\mathrm{E}$ group than expected, but the profile of this hormone was also similar to pregnancy.

Ovariectomy was found to produce an increase in body weight which was prevented by treatment with $17 \beta-$ estradiol, but not with progesterone or a combination of both hormones (Fig. 3). These results are in line with other authors (Wade 1975, Blaustein et al. 1976, Bailey \& Ahmed-Sorour 1980, Kalu et al. 1994). The increase in body weight in the V, P and EP groups was probably due to an increment in food intake, observed in other studies with ovariectomized animals (Wade 1975, Fishman 1976) or with pregnant rats (González et al. 1997, 1998). However, treatment with $17 \beta$-estradiol only causes a transient decrease in food intake (Blaustein \& Wade 1977). The $17 \beta$-estradiol treatment of ovariectomized rats maintained a normal leptin secretion and can regulate leptin gene expression and secretion in female rats, thus providing a better understanding of the possible anoretic effects of $17 \beta$-estradiol (Parsons et al. 1992, Sorenson \& Brelje 1997). The high level of progesterone (with low levels of $17 \beta$-estradiol) during the first half of pregnancy probably antagonizes the effect of $17 \beta$-estradiol and is responsible for net mother body weight gain.

In the present work we found that in groups treated with $17 \beta$-estradiol alone or $17 \beta$-estradiol and progesterone the fasting serum insulin concentration was significantly higher than in groups treated with progesterone alone or vehicle (Table 1). Our results therefore seem to indicate that $17 \beta$-estradiol is responsible for the increase in insulin secretion. Our findings might agree with several studies reporting that ovarian steroids affect $\beta$-cell function and 
$\mathbf{A}$

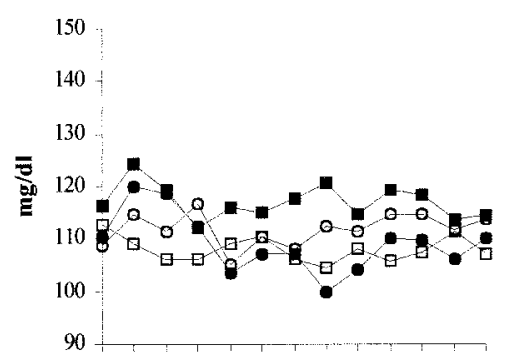

Day 6

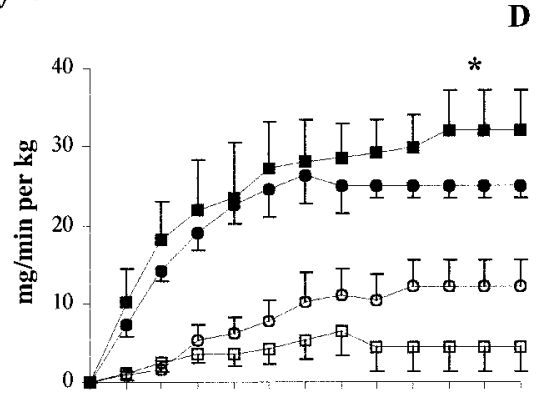

\section{Day 11}
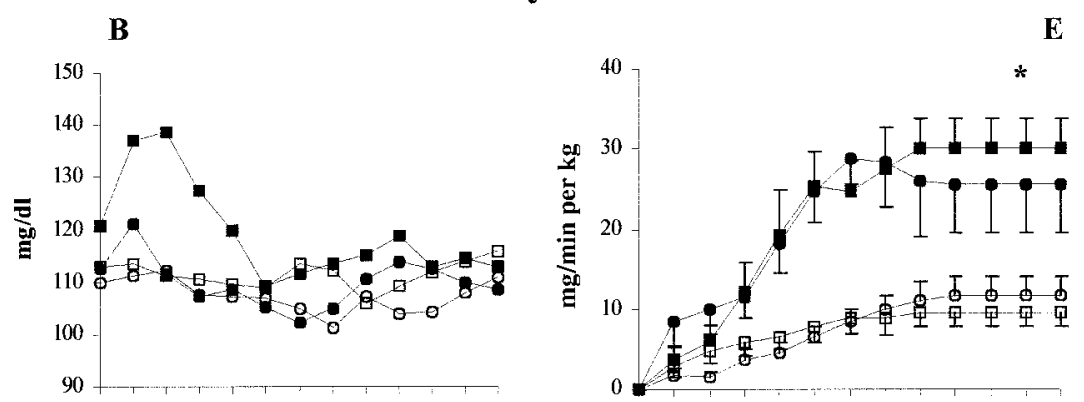

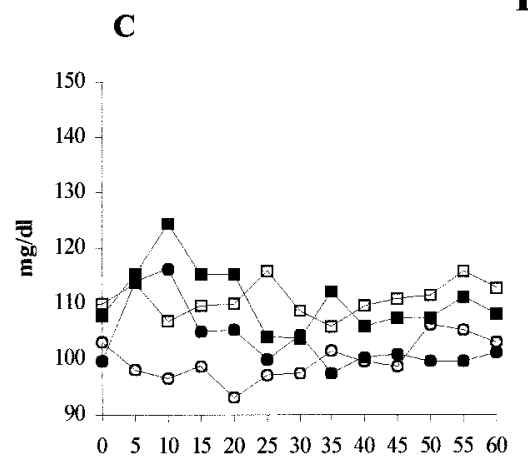

Time (min)

\section{Day 16}

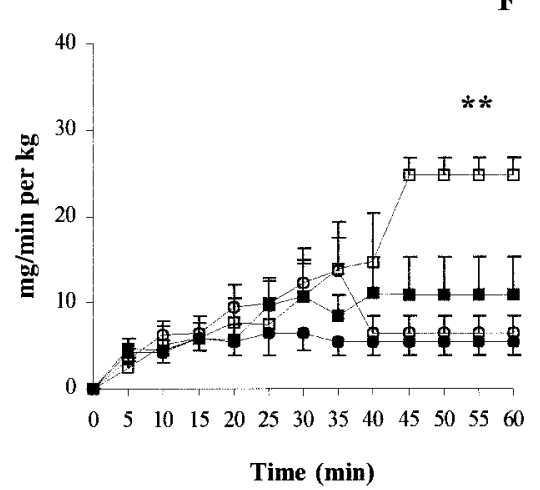

Figure 4 Blood glucose concentrations (A, B and C) and glucose infusion rate (D, E and F) during euglycemic clamp experiments. Data are shown for days 6, 11 and 16 of the experiment. Values are shown for vehicle $(\mathrm{V} ; \mathrm{O})$-, progesterone $(\mathrm{P} ; \square)$-, estradiol+ progesterone (EP; $)$ - and estradiol $(\mathrm{E} ; \mathbf{\square})$ - treated rats. Only significant differences are shown. Comparisons were made between the mean values from 40 to 60 min during euglycemic/hyperinsulinemic clamp experiments. Values are means \pm S.E.M. for six animals. ${ }^{*}=\mathrm{V}$ and $\mathrm{P}$ vs EP and $\mathrm{E} ;{ }^{* *}=\mathrm{P}$ vs $\mathrm{V}, \mathrm{EP}$ and $\mathrm{E}$.

glucose homeostasis by increasing insulin production through the induction of $\beta$-cell hypertrophy (YkiJarvinen 1984, Magnaterra et al. 1997, Zhu et al. 1998, Nieuwenhuizen et al. 1999) and, furthermore, with those observing that chronic progesterone therapy has no effect on either basal glucose or insulin levels compared with control rats (Nelson et al. 1994).

We have previously demonstrated (González et al. 1997, 1998) that the fasting serum insulin levels decreased between days 5 and 10 and increased between days 10 and 


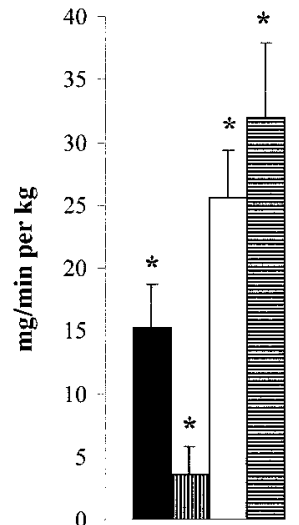

6

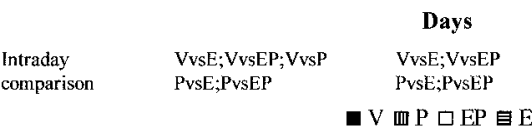

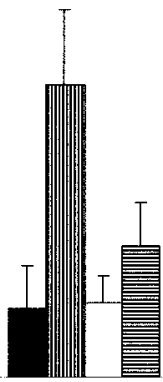

16
VvsP;PvsE;PvsEP

Figure 5 Comparison of glucose infusion rates of vehicle (V)-, progesterone (P)-, estradiol+progesterone (EP)- and estradiol (E)-treated rats. Glucose infusion rate was assessed as the mean values from 40 to 60 min during euglycemic hyperinsulinemic clamp experiments. Values are means \pm S.E.M. for six animals. Only significant differences are shown. ${ }^{*}=6$ vs $16 ;{ }^{* *}=11$ vs 16.

15 of pregnancy, findings in line with other studies (Bliss et al. 1990, Parsons et al. 1992, Muñoz et al. 1995). However, in this work, the fasting serum insulin significantly decreased between days 11 and 16 of treatment in the EP group. We consider that this result might be due to the high levels of $17 \beta$-estradiol in the EP group and that there may be a complex interaction between the pregnancy steroid and lactogenic hormones which are present during normal pregnancy but which are absent in our experimental design, whereby the steroids may be stimulatory, facilitatory or inhibitory depending on the concentration and/or duration of exposure of the hormones to the islets (Sorenson et al. 1993). The use of the rat model to examine the effect of progesterone and/or $17 \beta$-estradiol on glucose homeostasis creates a limitation in the volume of blood that can be removed and, consequently, restricts the number of parameters that can be measured during the study and their frequency of measurement. We cannot therefore exclude the possibility that circulating concentrations of other glucoregulatory hormones (e.g. glucagon, cortisol, prolactin, etc.) may have been altered by progesterone and/or $17 \beta$-estradiol treatment. We think that the differences between basal insulin levels and insulin levels after clamp are the result of a different insulin clearance rate. The liver is the most important tissue for insulin clearance, and the first step in insulin clearance is the binding of insulin to the specific receptor in the cellular membrane. Our hypothesis is that the action of estradiol and progesterone on insulin sensitivity is focused on the insulin receptor, and we suggest that the amount of insulin receptor in the liver could be modified by the concentration of sex hormones.

In the light of the clamp experiments (Figs 4 and 5), it could be said that progesterone treatment increases the insulin sensitivity at the end of the experiment (the progesterone-treated group at day 16 (P16) being more sensitive than P6 and P11), but treatment with $17 \beta$ estradiol causes a decrease in the insulin sensitivity at the end of the experiment (E6 and E11 being more sensitive than E16). On the other hand, low concentrations of progesterone (days 6 and 11) produced a decrease in insulin sensitivity while $17 \beta$-estradiol or vehicle brought about an increase in insulin sensitivity $(\mathrm{V}, \mathrm{EP}$ and $\mathrm{E}$ more sensitive than $P$ at days 6 and 11). These results are in agreement with studies reporting that estrogens increase sensitivity to the actions of insulin (Kalkhoff 1975), others showing that progesterone administration decreases insulin sensitivity in rats (Ryan \& Enns 1988, Leturque et al. 1989, Córdova et al. 1991) and other works suggesting that estradiol treatment seems to maintain insulin sensitivity in female rats (Holmäng \& Björntorp 1992, Holmäng et al. 1992). However, we do not totally agree, because at day 16 , when the progesterone plasma concentration of late pregnancy in the rat is reached, the $\mathrm{P}$ group is more sensitive than the EP and E groups. Therefore, we consider that the role of progesterone during early pregnancy, with low concentrations of $17 \beta$-estradiol, is to diminish insulin sensitivity while, in this period, the low concentration of $17 \beta$-estradiol favors insulin sensitivity. Nevertheless, during late pregnancy, the high concentrations of progesterone could be increasing insulin sensitivity but, in this period, the high concentrations of $17 \beta$-estradiol counteracted the effect of progesterone.

The present work seems to contradict the role that several studies attribute to progesterone (Leturque et al. 1987, Córdova et al. 1991, Lindheim et al. 1993, 1994, Kumagai et al. 1993). We consider that insulin sensitivity is influenced by sex hormone concentration, so progesterone per se increases insulin sensitivity at high concentrations and $17 \beta$-estradiol per se augments insulin sensitivity at low concentrations but disminishes insulin sensitivity at high concentrations.

It is likely that, during gestation, the roles of both hormones are complementary and are intimately related to the other hormones which are elevated during normal gestation in the rat (e.g. growth hormone, lactogenic hormones). In addition, it is feasible to think that the development of systemic insulin resistance to insulin action, related to pregnancy, is somewhat different if we study the role of both hormones on the three most important target tissues of insulin: liver, skeletal muscle and adipose tissue. In this way, during early pregnancy, progesterone could be favoring insulin resistance in some tissues (principally the liver) and could be increasing insulin sensitivity in others (mainly skeletal muscle and adipose tissue) while, during later pregnancy, the increase 
in concentrations of this hormone could be favoring insulin sensitivity in the former (liver) and could be decreasing insulin sensitivity in the latter (skeletal muscle and adipose tissue), the action of $17 \beta$-estradiol antagonizing the action of progesterone in both periods of gestation.

In summary, our results seem to suggest that the absence of female steroid hormones results in a decreased insulin sensitivity. $17 \beta$-Estradiol could be responsible for the increase in insulin sensitivity during early pregnancy when the plasma concentrations of $17 \beta$-estradiol and progesterone are low. However, during late pregnancy, when the plasma concentrations of $17 \beta$-estradiol and progesterone are high, the role of $17 \beta$-estradiol could be to antagonize the effect of progesterone diminishing insulin sensitivity. The effect of both hormones as proposed in this paper could appear to be altered in the presence of high plasma concentrations of the lactogenic hormones and growth hormone, just as occurs during normal pregnancy.

\section{Acknowledgements}

This study was supported by grants from the University of Oviedo (NP-98-516-3) and the Dirección Regional de Universidades e Investigación del Principado de Asturias as part of the II Plan Regional de Investigación (PP-SAL98-02).

\section{References}

Aerts L, Van Assche FA, Faure A \& Sutter-Dub MT 1980 Effects of treatment with progesterone and oestradiol-17 $\beta$ on the endocrine pancreas in ovariectomized rats: ultrastructural variations in the $\beta$ cells. Journal of Endocrinology 84 317-320.

Baaziz N \& Curry DL 1993 Synthesis-secretion coupling of insulin: effect of pregnancy and lactation. Pancreas 8 316-324.

Bailey CJ \& Ahmed-Sorour H 1980 Role of ovarian hormones in the long-term control of glucose homeostasis. Diabetologia 19 475-481.

Blaustein JD \& Wade GN 1977 Ovarian hormones and meal patterns in rats: effects of progesterone and role of gastrointestinal transit. Physiology and Behaviour 19 23-27.

Blaustein JD, Gentry RT, Roy EJ \& Wade GN 1976 Effects of ovariectomy and estradiol on body weight and food intake in gold thioglucose-treatment mice. Physiology and Behaviour 17 1027-1030.

Bliss CB, Wiedenkeller DE \& Sharp GWG 1990 Maternal diet and insulin secretion in islets of lactating, nonlactating, and young rats. American Journal of Physiology 259 E568-E575.

Córdova P, Kaaya A, Richard O \& Sutter-Dub MT 1991 Inhibition of glucose metabolism by progesterone in adipocytes: role of protein synthesis. Canadian Journal of Physiology and Pharmacology 69 1861-1867.

Escrivá F, Rodríguez C, Cacho J, Alvarez C, Portha B \& PascualLeone AM 1992 Glucose utilization and insulin action in adult rats submitted to prolonged food restriction. American Journal of Physiology 263 E1-E7.

Fernández A, Ordás I, Gutiérrez JM, González C, Fernández S \& Patterson AM 1993 The rehabilitation of malnourished rats, at the end of the lactation period, with two different sources of dietary lipids: soybean and olive oils. Nutrition (Life Sciences Advances) 12 79-88.
Fishman J 1976 Appetite and sex hormones. In Dahlem Workshop on Appetite and Food Intake, pp 207-218. Ed T Silverston. Berlin: Dahlem Konferenzen.

Godsland IF, Walton C, Felton C, Proudler A, Patel A \& Wynn V 1991 Insulin resistance, secretion, and metabolism in users of oral contraceptives. Journal of Clinical Endocrinology and Metabolism $\mathbf{7 4}$ 64-70.

González C, Díaz F, Fernández S \& Patterson AM 1997 Role of $17 \beta$-estradiol and progesterone on glucose homeostasis: effects of food restriction (50\%) in pregnant and non pregnant rats. Journal of Endocrinological Investigation 20 397-403.

González C, Díaz F, Fernández S \& Patterson AM 1998 Pregnancy in rats and food restriction (50\%): insulin response in relation to serum lipids and lipoprotein levels. Nutrition Research 18 1235-1244.

Gutiérrez JM, Alvarez I, Díaz F, Fernández S \& Menéndez-Patterson A 1991 Influence of Nitrogen balance and intestinal glucose absortion on growth of rats recovery from early undernutrition. Nutrition Research 11 1427-1437.

Hay WW Jr, Sparks JW, Wilkening RB, Battglia FC \& Meschia G 1984 Effects of insulin on glucose uptake by the maternal hindlimb and uterus, and by the fetus in conscious pregnant sheep. Journal of Endocrinology 100 119-124.

Herrera E, Lasunción MA, Palacín M, Zorzano A \& Bonet B 1991 Intermediary metabolism in pregnancy. Diabetes 40 83-88.

Holmäng A \& Björntorp P 1992 The effects of testosterone on insulin sensitivity in male rats. Acta Physiologica Scandinavica 146 505-510.

Holmäng A, Larsson BM, Brzezinska Z \& Björntorp P 1992 The effects of short-term testosterone exposure on insulin sensitivity of muscles in female rats. American Journal of Physiology 262 E851-E855.

Howell SL, Tyhurst M \& Green IC 1977 Direct effects of progesterone on rat islet of Langerhans in vivo and in tissue culture. Diabetologia 13 579-583.

Kalkhoff RK 1975 Effects of oral contraceptive agents on carbohydrate metabolism. Journal of Steroids and Biochemistry 6 949-956.

Kalu DN, Arjmandi BH, Liu CC, Salih MA \& Birnbaum RS 1994 Effects of ovariectomy and estrogen on serum levels of insulin-like growth factor-I and insulin-like growth factor binding protein-3. Bone and Mineral 25 135-148.

Kauffman RC, Khosho FK, Verhulst SJ \& Amankwah KS 1991 Effects of pregnancy on glucose metabolism in glucose intolerant 'B' Wistar rats. American Journal of Physiology 8 11-14.

Kraegen EW, James DE, Bennett SP \& Chisholm DJ 1983 in vivo insulin sensitivity in the rat determined by euglycemic clamp. American Journal of Physiology 245 E1-E7.

Kumagai S, Holmäng A \& Björntorp P 1993 The effects of oestrogen and progesterone on insulin sensitivity in female rats. Acta Physiologica Scandinavica 149 91-97.

Leturque A, Ferré P, Burnol AF, Kande J, Maulard P \& Girard J 1986 Glucose utilization rates and insulin sensitivity in vivo in tissues of virgin and pregnant rats. Diabetes 35 172-177.

Leturque A, Hauguel S, Ferré P \& Girard J 1987 Glucose metabolism in pregnancy. Biology of the Neonate 51 64-69.

Leturque A, Hauguel S, Sutter-Dub M, Maulard P \& Girard J 1989 Effects of placental lactogen and progesterone on insulin stimulated glucose metabolism in rat muscle in vitro. Diabetes and Metabolism 15 176-181.

Lindheim SR, Presser SC, Ditkoff EC, Vijod MA, Stanzyk FZ \& Lobo RA 1993 A possible bimodal effect of estrogen on insulin sensitivity in postmenopausal women and the attenuating effect of added progestin. Fertility and Sterility $60664-667$.

Lindheim SR, Vijod MA, Duffy DM, Stanzyk FZ, Kojima T \& Lobo RA 1994 The route of administration influences the effect of estrogen on insulin sensitivity in postmenopausal women. Fertility and Sterility 62 1176-1180.

Magnaterra R, Porzio O, Piemonte F, Bertoli A, Sesti G, Lauro D, Marlier LN, Federici G \& Borboni P 1997 The effects of 
pregnancy steroids on adaptation of beta cells to pregnancy involve the pancreatic glucose sensor glucokinase. Journal of Endocrinology 155 247-253.

Marsden PJ, Murdoch A \& Taylor R 1996 Adipocyte insulin action during the normal menstrual cycle. Human Reproduction $\mathbf{1 1}$ 968-974.

Metcalfe J, Stock MK \& Barron DH 1994 Maternal physiology during gestation. In The Physiology of Reproduction, pp 2145-2176. Eds E Knobil \& JD Neill. New York: Raven Press Ltd.

Muñoz C, Lopez-Luna P \& Herrera E 1995 Glucose and insulin tolerance test in the rat on different days of gestation. Biology of the Neonate 68 282-291.

Nelson T, Shulman G, Grainger D \& Diamond MP 1994 Progesterone administration induced impairment of insulin suppression of hepatic glucose production. Fertility and Sterility 62 491-496.

Nieuwenhuizen AG, Schuiling GA, Liem SM, Moes H, Koiter TR \& Uilenbroek JT 1999 Progesterone stimulates pancreatic cell proliferation in vivo. European Journal of Endocrinology $140256-$ 263.

Parsons JA, Brelje TC \& Sorenson RL 1992 Adaptation of islets of Langerhans to pregnancy: increased islet cell proliferation and insulin secretion correlates with the onset of placental lactogen secretion. Endocrinology 130 1459-1466.

Polderman KH, Gooren LJG, Asscheman H, Bakker A \& Heine RJ 1994 Induction of insulin resistance by androgens and estrogens. Journal of Clinical Endocrinology and Metabolism 79 265-271.

Poretsky L 1991 On the paradox of insulin-induced hyperandrogenism in insulin-resistant states. Endocrine Reviews 12 3-13.

Rankin JHG, Jodarski G \& Shanahan MR 1986 Maternal insulin and placental 3-O-methyl glucose transport. Journal of Developmental Physiology 8 247-253.

Ryan AR \& Enns L 1988 Role of gestational hormones in the induction of insulin resistance. Journal of Clinical Endocrinology and Metabolism 67 341-347.

Saad MJA, Maeda L, Brenelli SL, Carvalho CRO, Paiva RS \& Velloso LA 1997 Defects in insulin signal transduction in liver and muscle of pregnant rats. Diabetologia 40 179-186.

Simonson DC \& Widom B 1991 Menstrual cycle associated changes in glucose metabolism in women with IDDM. Diabetes 39 S1.
Sorenson RL \& Brelje TC 1997 Adaptation of islets of Langerhans to pregnancy: beta-cell growth, enhanced insulin secretion and the role of lactogenic hormones. Hormonal and Metabolic Research 29 301-307.

Sorenson RL, Brelje TC \& Roth C 1993 Effects of steroid and lactogenic hormones on islets of Langerhans: a new hypothesis for the role of pregnancy steroids in the adaptation of islets to pregnancy. Endocrinology 133 2227-2234.

Spellacy WN 1982 Carbohydrate metabolism during treatment with estrogen, progestogen and low-dose oral contraceptives. American Journal of Obstetrics and Gynecology 142 732-734.

Sutter-Dub MT \& Dazey B 1979 Rôle de la progestérone dans l'insulino-résistance pendant la gestation chez la ratte. Annales d'Endocrinologie 40 37-38.

Sutter-Dub MT, Faure A, Aerts L \& Van Assche FA 1978 Effects of progesterone and $17-\beta$-oestradiol treatments on the pancreatic $B$ cell in castrated female rats. Journal de Physiologie 74 725-730.

Valdes CT \& Elkind-Hirsch KE 1991 Intravenous glucose tolerance test-derived insulin sensitivity changes during the menstrual cycle. Journal of Clinical Endocrinology and Metabolism 72 642-646.

Wade GN 1975 Some effects of ovarian hormones on food intake and body weight in female rats. Journal of Comparative Physiology and Psychology 88 183-193.

Watanabe RM, Azen CG, Roy S, Perlman JA \& Bergman RN 1994 Defects in carbohydrate metabolism in oral contraceptive users without apparent metabolic risk factors. Journal of Clinical Endocrinology and Metabolism 79 1277-1283.

Yki-Jarvinen H 1984 Sex and insulin sensitivity. Metabolism 33 1011-1015.

Zhu M, Mizuno A, Kuwajima M, Ogino T, Murakami T, Noma Y, Sano T \& Shima K 1998 Ovarian hormone-induced beta-cell hypertrophy contributes to the homeostatic control of beta-cell mass in OLETF female rat, a model of type II diabetes. Diabetologia $\mathbf{4 1}$ 799-805.

Received 16 November 1999

Revised manuscript received 7 March 2000 Accepted 6 April 2000 